\title{
EPR, NEXAFS STUDY AND MAGNETIC PROPERTIES OF Fe-DOPED FERROELECTRIC CERAMICS
}

\author{
N. A. Zhuk1, V. P. Lutoev², B. A. Makeev², N. V. Chezhina ${ }^{3}$, V. A. Belyy ${ }^{4}$ \\ and S. V. Nekipelov ${ }^{1,5}$
}

${ }^{1}$ Syktyvkar State University, Oktjabrskij prospect, 55, Syktyvkar, Republic of Komi, 167001, Russia, Institute of Geology of the Komi Science Center UB RAS, Pervomaiskaya st. 54, Syktyvkar, Republic of Komi,167982, Russia

${ }^{3}$ St. Petersburg State University, Universitetsky pr. 26, St. Petersburg, 198504, Russia ${ }^{4}$ Institute of Chemistry of the Komi Science Center UB RAS, Pervomaiskaya st. 48, Syktyvkar, 167982, Republic of Komi, Russia

${ }^{5}$ Institute of Physics and Mathematics of the Komi Science Center UB RAS, Oplesnina st. 4, Syktyvkar, Republic of Komi,167982, Russia

Received: February 19, 2018

\begin{abstract}
Magnetic susceptibility and EPR of iron-containing solid solutions with layered perovskite-like structure $\mathrm{Bi}_{2} \mathrm{BaNb}_{2-2 x} \mathrm{Fe}_{2 x} \mathrm{O}_{9-\delta}$ and $\mathrm{Bi}_{5} \mathrm{Nb}_{3-3 x} \mathrm{Fe}_{3 x} \mathrm{O}_{15-\delta}$ have been studied. The solid solutions $\mathrm{Bi}_{2} \mathrm{BaNb}_{2-2 x} \mathrm{Fe}_{2 x} \mathrm{O}_{9-\delta}$ as well as iron oxides $\mathrm{FeO}, \mathrm{Fe}_{2} \mathrm{O}_{3}$, and $\mathrm{Fe}_{3} \mathrm{O}_{4}$ were studied by the NEXAFS spectroscopy. The formation of exchange-bound aggregates of $\mathrm{Fe}(\mathrm{III})$ atoms with antiferroand ferromagnetic exchange types has been found in the solid solutions. In the ESR spectra of the solid solution samples, the lines with $g \approx 2.0$ and $g=4.27$ having a weak shoulder at $g \sim 8$ were attributed to $\mathrm{Fe}(\mathrm{III})$ atoms in the octahedral field with strong rhombic distortion.
\end{abstract}

\section{INTRODUCTION}

The majority of bismuth-containing compounds with layered perovskite-like structure, analogues of the so called Aurivillius phases, are of practical and theoretical interest owing to their ferroelectric properties [1-7]. The composition of such compounds is described by the general formula $\left(\mathrm{Bi}_{2} \mathrm{O}_{2}\right)\left(\mathrm{A}_{n-1} \mathrm{~B}_{n} \mathrm{O}_{3 n+1}\right)$, where the bismuth-oxygen layers $\mathrm{Bi}_{2} \mathrm{O}_{2}$ consist of $\mathrm{BiO}_{4}$ pyramids bound to each other by base edges and $\mathrm{A}_{n-1} \mathrm{~B}_{n} \mathrm{O}_{3 n+1}$ are perovskite-like fragments consisting of $\mathrm{BO}_{6}$ octahedra bound by vertices. The large cations $A$ are located in the cubic octahedral sites between them [8-12]. The coefficient $n$ in the formula corresponds to the number of $\mathrm{BO}_{6}$ octahedra forming the thickness of the perovskite-like fragment. Barium-bismuth niobate $\mathrm{Bi}_{2} \mathrm{BaNb}_{2} \mathrm{O}_{9}$ is a typical representative of this group of compounds. Its struc- ture is described by the space group A2 am ( $a=b$ $=0.5567, c=2.5634 \mathrm{~nm}$ ) and is characterized by the bismuth-oxygen layers alternating with the perovskite-like blocks formed by two layers of niobium-oxygen octahedral [13]. Alongside with the layered compounds which contain the uniform perovskite-like fragments, there are the so-called mixed or hybrid layered compounds $\left(\mathrm{Bi}_{2} \mathrm{O}_{2}\right)$ $\left(\mathrm{A}_{n-1} \mathrm{~B}_{n} \mathrm{O}_{3 n+1}\right) \ldots\left(\mathrm{Bi}_{2} \mathrm{O}_{2}\right)\left(\mathrm{A}_{m-1} \mathrm{~B}_{m} \mathrm{O}_{3 m+1}\right)$ [14-17]. Their structure consists of alternating perovskite-like fragments of various widths. Bismuth niobate $\mathrm{Bi}_{5} \mathrm{Nb}_{3} \mathrm{O}_{15}$ belongs to the group of mixed layered compounds. Its structure is characterized by the ordered alternating of fragments formed by one and two niobiumoxygen octahedra. Therefore, its structure can be described as $\left(\mathrm{Bi}_{2} \mathrm{O}_{2}\right)\left(\mathrm{NbO}_{4}\right)\left(\mathrm{Bi}_{2} \mathrm{O}_{2}\right)\left(\mathrm{BiNb}_{2} \mathrm{O}_{7}\right)$, with $n=1$ and $m=3$. Oxygen-niobium octahedra are bound by side vertices and are arranged in the $a-b$ plane of

Corresponding author: N.A.Zhuk, e-mail:nzhuck@mail.ru 
the crystal, the $\mathrm{Nb}-\mathrm{O}-\mathrm{Nb}$ bond angle is $180^{\circ}$. The layers of the octahedra are separated by the bismuth-oxygen layers $\mathrm{Bi}_{2} \mathrm{O}_{2}$ formed by the $\mathrm{BiO}_{4}$ pyramids and joined by the base edges.

The present work discusses the results of the ESR and static magnetic susceptibility measurements of electron state and the nature of exchange interactions between iron atoms in the solid solutions of bismuth niobates $\mathrm{Bi}_{2} \mathrm{BaNb}_{2} \mathrm{O}_{9}$ and $\mathrm{Bi}_{5} \mathrm{Nb}_{3} \mathrm{O}_{15}$ with layered perovskite-like structure, which were obtained by heterovalent substitution of niobium (V) with iron atoms (III). The iron-containing solid solutions $\mathrm{Bi}_{2} \mathrm{BaNb}_{2-2 x} \mathrm{Fe}_{2 x} \mathrm{O}_{9-\delta}$ and $\mathrm{Bi}_{5} \mathrm{Nb}_{3-3 x} \mathrm{Fe}_{3 x} \mathrm{O}_{15-\delta}$ have been studied with $0.005 \leq x \leq 0.06$ [18,19]. Iron (III) atoms, which are close in size to niobium (V) atoms, isomorphously substitute octahedral cation sites in the perovskite layers $\left[\mathrm{R}(\mathrm{Nb}(\mathrm{V}))_{\mathrm{CN}=6}=0.064\right.$ $\left.\mathrm{nm} ; \mathrm{R}(\mathrm{Fe}(\mathrm{III}))_{\mathrm{CN}=6 \text { (high spin) }}=0.0645 \mathrm{~nm}\right][20]$. The single-phase nature of the samples was proved by the methods of scanning electron microscopy and Xray analyses (Figs. 1 and 2 ).

\section{EXPERIMENTAL}

The synthesis of the solid solutions was carried out by the standard ceramic procedure from specialpurity grade bismuth(III), niobium(V), and iron(III) oxides at $650^{\circ} \mathrm{C}$ è $1100^{\circ} \mathrm{C}$. Phase composition of the products was determined by means of electron scanning microscopy (using a Tescan VEGA $3 L M N$ electron scanning microscope and a INCA Energy 450 energy-dispersive spectrometer) and X-ray diffraction analysis using a DRON-4-13 diffractometer
(CuK ${ }_{\alpha}$ radiation). The cell unit parameters of solid solutions were calculated using the CSD software package [21].

The magnetic susceptibility of the samples of the solid solutions was measured by the Faraday method in the temperature range of $77-400 \mathrm{~K}$ at 16 fixed temperatures and at the magnetic field strength of $7240,6330,5230$, and 3640 Oe. A semicommercial installation created in the laboratory of magnetochemistry of St. Petersburg State University and consisting of an electromagnet, an electronic balance, and cryostate was used for magnetic susceptibility measurements.

The ESR spectra of polycrystalline samples of iron-containing solid solutions of bismuth niobate were recorded on an SE/X 2547 radio spectrometer of X-diapason (RadioPAN). The spectra were recorded using an RX102 rectangular resonator (TE 102 mode) at room temperature as the first derivative at $\mathrm{HF}$ modulation frequency of $100 \mathrm{MHz}$ with amplitude of $0.25 \mathrm{mT}$ and SHF field power of 35 $\mathrm{mWt}$. A weighed specimen of about $100 \mathrm{mg}$ was placed in a quartz tube with the external diameter of $4 \mathrm{~mm}$. To calibrate the amplification of the apparatus, we used the ESR signal of a miniature reference sample (anthracite, a singlet line with $g_{0}=2.0032, \Delta B p p=0.5 \mathrm{mT}$ ), the quartz ampule with the reference sample was rigidly fastened in the resonator coaxially to the test tube with a sample. The spectrum of each sample was recorded in the magnetic field range of $0-700 \mathrm{mT}$ and the line of the reference sample was recorded separately with

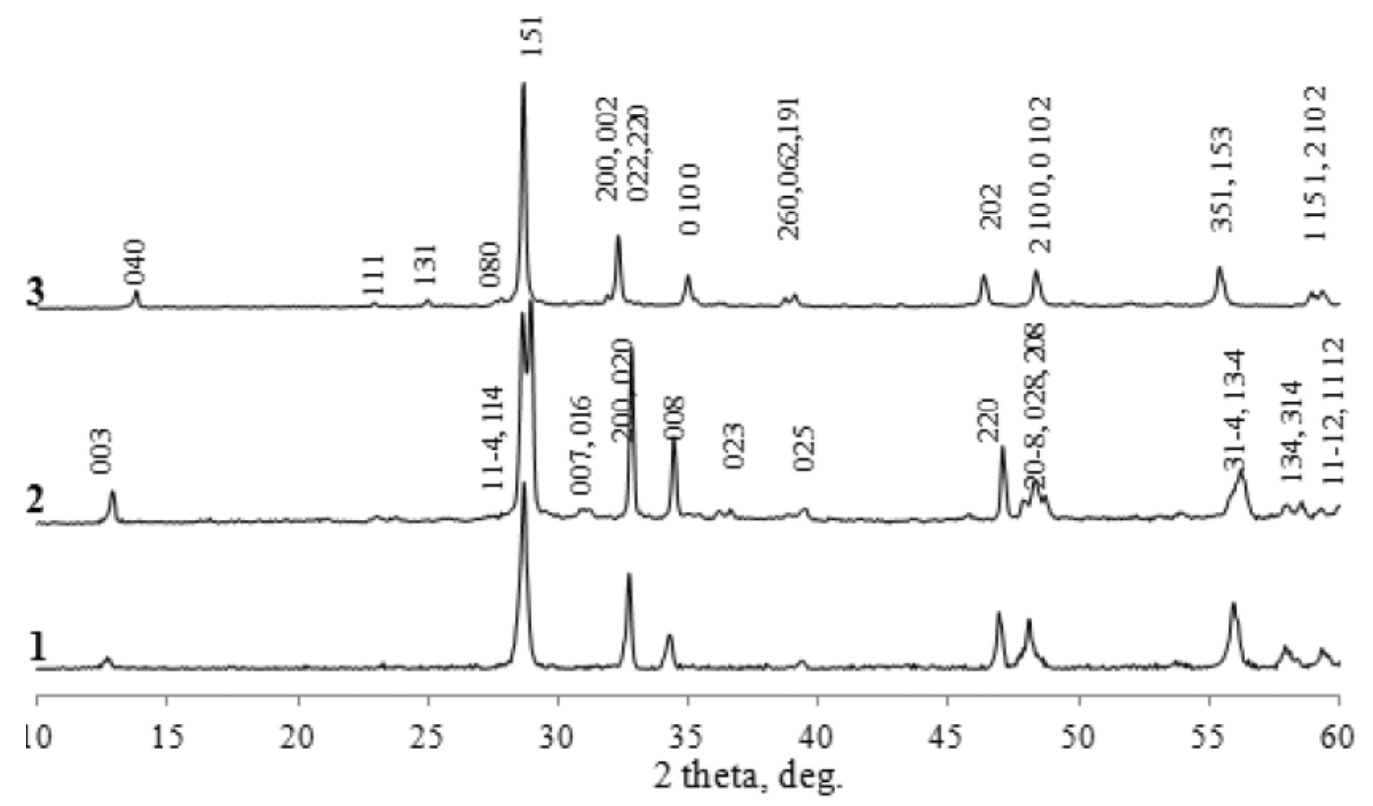

Fig. 1. X-ray patterns of $\mathrm{Bi}_{5} \mathrm{Nb}_{3} \mathrm{O}_{15}$ (1) and the solid solutions $\mathrm{Bi}_{5} \mathrm{Nb}_{2.82} \mathrm{Fe}_{0.18} \mathrm{O}_{15-8}$ (2), and $\mathrm{Bi}_{2} \mathrm{BaNb}_{1.88}-$ $\mathrm{Fe}_{0.12} \mathrm{O}_{9.8}(3)$. 

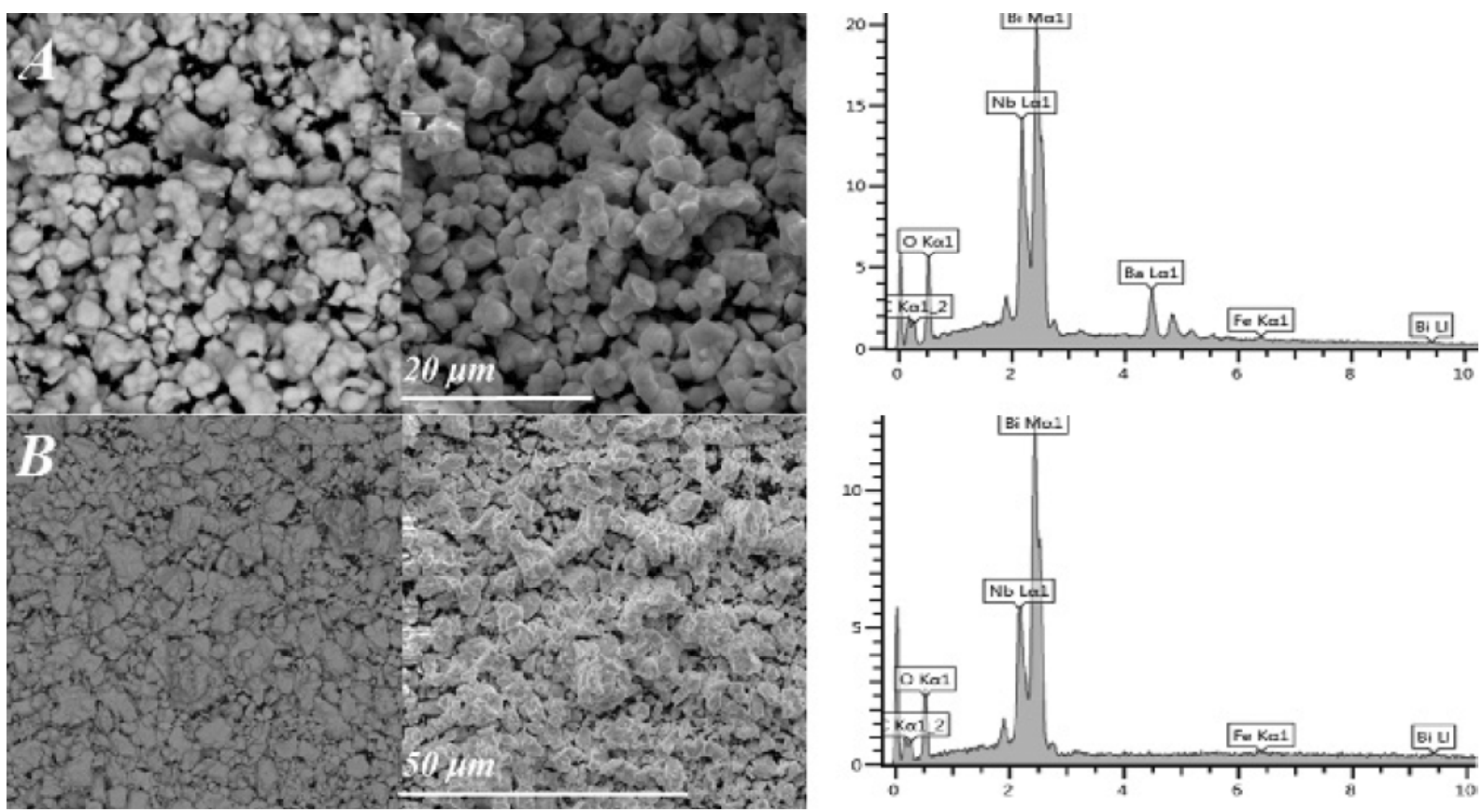

Fig. 2. EDS spectrums and surface photomicrographs of the sample $\mathrm{Bi}_{2} \mathrm{BaNb}_{1.88} \mathrm{Fe}_{0.12} \mathrm{O}_{9-\delta}$ (a) and $\mathrm{Bi}_{5} \mathrm{Nb}_{2.82} \mathrm{Fe}_{0.18} \mathrm{O}_{15-\delta}$ (b) in the mode of secondary and elastic backscattered electrons.

the involute of about $5 \mathrm{mT}$. The spectra of the samples were led to equal intensities of the reference sample line and normalized to an equal mass of $100 \mathrm{mg}$.

The NEXAFS (near-edge X-ray absorption fine structure) of the Fe2p-absorption spectra of the ironcontaining solid solutions and iron oxides was obtained using a synchrotron radiation source at the Russian-German beamline at BESSY-II (Berlin) [22]. All the spectra were recorded in the total electron yield (TEY) mode [23].

\section{RESULTS}

It was found that the solid solutions $\mathrm{Bi}_{5} \mathrm{Nb}_{3-3 x} \mathrm{Fe}_{3 x}-$ $\mathrm{O}_{15-8}$ with $0.005 \leq x \leq 0.06$ undergo monoclinic distortion of the tetragonal unit cell, the $X$-ray patterns of the solid solutions were interpreted based on the space group $P 2 / m$ [24]. The unit cell parameter a decreases to $0.5457 \mathrm{~nm}$, and the parameters $b$ and $c$ increase to 0.5462 and $2.091 \mathrm{~nm}$, respectively, the á angle changes from $90^{\circ}$ to $90.8^{\circ}(x=0.06)$. The orthorhombic unit cell parameters of the solid solutions $\mathrm{Bi}_{2} \mathrm{BaNb}_{2-2 x} \mathrm{Fe}_{2 x} \mathrm{O}_{9-\delta}$ are insignificantly changing as the fraction of iron increases from $a=$ $0.5545 \mathrm{~nm}, c=2.5639 \mathrm{~nm}, b=0.5538 \mathrm{~nm}(x=$ 0.005 ) to $a=0.5539 \mathrm{~nm}, c=2.5651 \mathrm{~nm}, b=0.5540$ $\mathrm{nm}(x=0.060)[18,19]$.

Using the measured magnetic susceptibility of the solid solutions, we calculated the paramagnetic components of the magnetic susceptibility and ef- fective magnetic moments of iron atoms at various temperatures and concentrations of the solid solutions.

The isotherms of paramagnetic component of magnetic susceptibility of iron atoms in $\mathrm{Bi}_{2} \mathrm{Ba}$ $\mathrm{Nb}_{2-2 x} \mathrm{Fe}_{2 x} \mathrm{O}_{9-\delta}$ and $\mathrm{Bi}_{5} \mathrm{Nb}_{3-3 x} \mathrm{Fe}_{3 x} \mathrm{O}_{15-\delta}$ are typical for antiferromagnets, their comparison is shown in Fig. 3. The effective magnetic moments of single iron atoms calculated by extrapolating concentration dependencies of $\left[\chi^{\text {para }}(\mathrm{Fe})\right]$ to infinite dilution of the

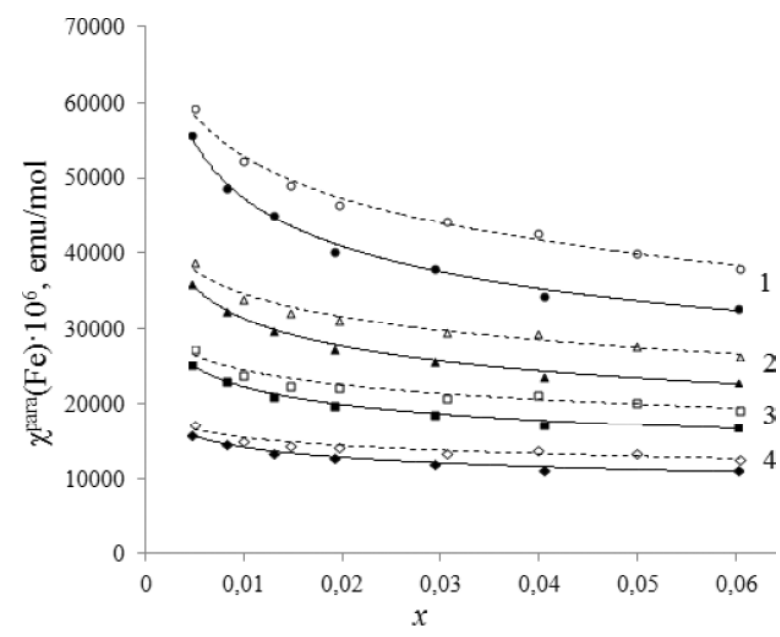

Fig. 3. Isotherms of paramagnetic component of magnetic susceptibility of the iron-containing solid solutions $\mathrm{Bi}_{2} \mathrm{BaNb}_{2-2 x} \mathrm{Fe}_{2 x} \mathrm{O}_{9-\delta}$ (dotted lines) and $\mathrm{Bi}_{5} \mathrm{Nb}_{3-3 x} \mathrm{Fe}_{3 x} \mathrm{O}_{15-\delta}$ (solid lines) at $90 \mathrm{~K}$ (1), 140K (2), 200K (3), 260K (4). 
solid solutions exceed pure-spin values and increase as the temperature increases from $6.69 \mu \mathrm{B}(90 \mathrm{~K})$ to $7.01 \mu \mathrm{B}(32 \mathrm{~K})\left(\mathrm{Bi}_{5} \mathrm{Nb}_{3-3 x} \mathrm{Fe}_{3 \mathrm{x}} \mathrm{O}_{15-\delta}\right)$ and from $7.35 \mu \mathrm{B}$ (90K) to $7.50 \mu \mathrm{B}(320 \mathrm{~K})\left(\mathrm{Bi}_{2} \mathrm{BaNb}_{2-2 x} \mathrm{Fe}_{2 x} \mathrm{O}_{9-\delta}\right)$.

Taking into account the fact that the increase in the effective magnetic moment of iron (III) atoms in comparison with the pure-spin values of $\mathrm{Fe}(\mathrm{III})\left(\mu_{\text {eff }}=\right.$ $5.92 \mu \mathrm{B}$, ground term $\left.{ }^{6} \mathrm{~A}_{1 \mathrm{~g}}\right)$ and $\mathrm{Fe}(\mathrm{II})\left(\mu_{\text {eff }}=4.9\right.$ $\mu \mathrm{B},{ }^{5} \mathrm{~T}_{2 \mathrm{~g}}$ ) can be caused neither by spin-orbit coupling, nor by zero field effects, we suggested that exchange-bound aggregates or clusters of iron (III) atoms with predominantly ferromagnetic type of exchange remain in the strongly diluted solutions with layered structure. The decrease in the paramagnetic component of magnetic susceptibility of iron atoms with increasing concentration of the solid solutions is associated with a manifestation of antiferromagnetic interactions between iron atoms. The temperature dependences of the effective magnetic moment of iron atoms in the solid solutions with various concentrations of paramagnetic atoms also support this assumption (Fig. 4).

In the ESR spectra of the samples of $\mathrm{Bi}_{2} \mathrm{Ba}-$ $\mathrm{Nb}_{2-2 x} \mathrm{Fe}_{2 x} \mathrm{O}_{9-\delta}$ and $\mathrm{Bi}_{5} \mathrm{Nb}_{3-3 x} \mathrm{Fe}_{3 x} \mathrm{O}_{15-\delta}$ solid solutions, at all $x$ values, there is an intensive asymmetric line in the region of low fields with $g$-factor of 4.27 having a weakly expressed shoulder at $g \sim 8$, and a strong broad $\left(\Delta B_{p p} \sim 90-130 \mathrm{mT}\right)$ band centered at about $g \sim 2.0$ (Fig. 5). The origin of the component with $g=4.27$ is associated with $\mathrm{Fe}^{3+}$ ions which are situated in strong crystal field with $D>h v_{\mathrm{SHF}}(\sim 9.4 \mathrm{MHz})$ and the maximum degree of rhombic distortion $E / D$ $\sim 1 / 3$. In this case the effective $g$-factor of the transition line between Kramers doublet levels $\pm 3 / 2$ becomes isotropic and equal to $4.27[25,26]$. The octahedral sites of iron atoms with strong rhombic distortion are probably associated with the appearance

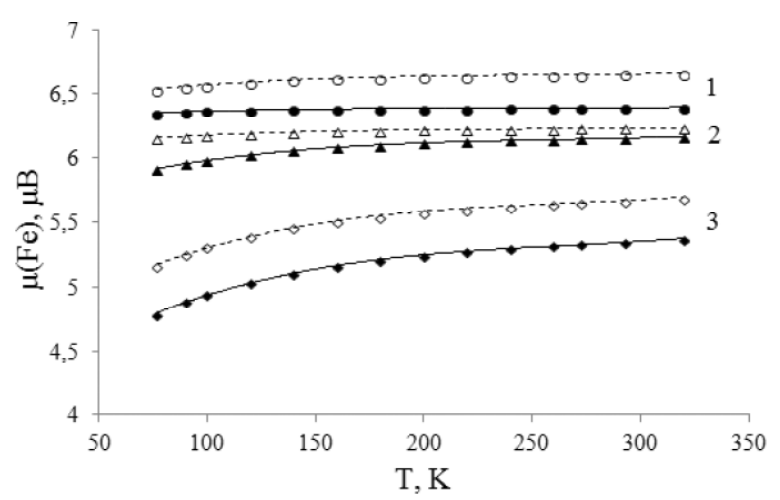

Fig. 4. Temperature dependencies of the effective magnetic moment of iron in the $\mathrm{Bi}_{2} \mathrm{BaNb}_{2-2 x} \mathrm{Fe}_{2 x} \mathrm{O}_{9-\delta}$ (dotted lines) and $\mathrm{Bi}_{5} \mathrm{Nb}_{3-3 x} \mathrm{Fe}_{3 x} \mathrm{O}_{15-8}$ (solid lines) solid solutions at $x=0.005$ (1), 0.01 (2), and 0.06 (3).

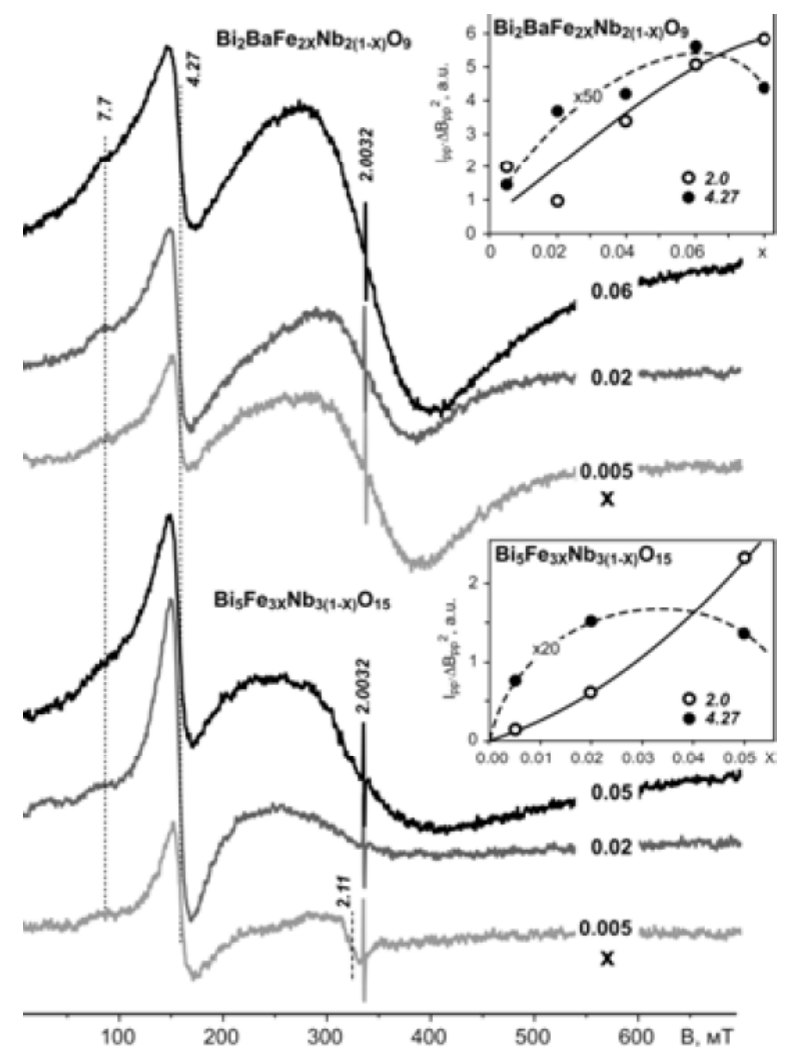

Fig. 5. ESR spectra of the samples of the $\mathrm{Bi}_{2} \mathrm{Ba}-$ $\mathrm{Nb}_{2-2 x} \mathrm{Fe}_{2 x} \mathrm{O}_{9-8}$ and $\mathrm{Bi}_{5} \mathrm{Nb}_{3-3 x} \mathrm{Fe}_{3 x} \mathrm{O}_{15-8}$ solid solutions at various values of index $x, \Delta B p p$ width of an individual line is $15 \mathrm{mT}$. The inset shows the dependences of the integral intensities of the lines with $g=4.27$ and 2.0 on the $x$ value.

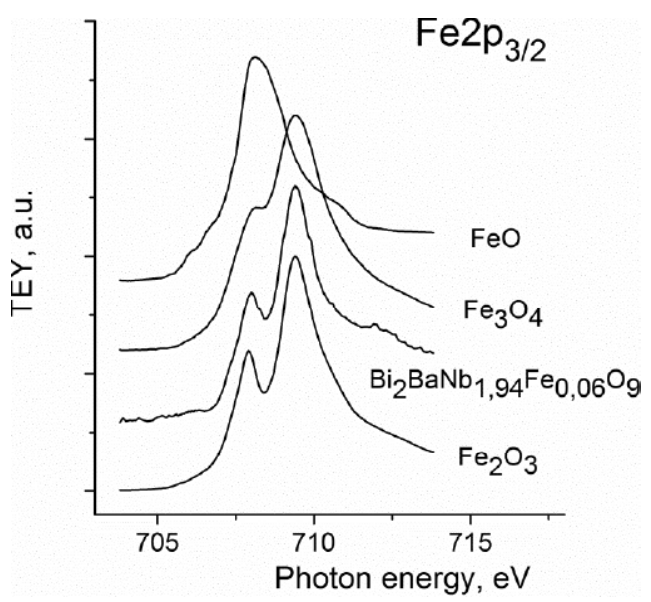

Fig. 6 NEXAFS Fe2 $2 p_{3 / 2}$ - spectra of the iron-containing solid solutions $\mathrm{Bi}_{2} \mathrm{BaNb}_{2-2 x} \mathrm{Fe}_{2 x} \mathrm{O}_{9-\delta}$, and iron oxides $\mathrm{FeO}, \mathrm{Fe}_{2} \mathrm{O}_{3}$, and $\mathrm{Fe}_{3} \mathrm{O}_{4}$.

of oxygen vacancies due to the compensation of excessive charge arising upon the heterovalent substitution of $\mathrm{Nb}(\mathrm{V})$ atoms with $\mathrm{Fe}(\mathrm{III})$. The absence of noticeable structuration of the band at $\mathrm{g} \sim 2.0$ and the emergence of the signal in the samples with high iron concentration point to its origin from either 
clusters or Fe(III) ions in weakly distorted octahedral sites.

As the concentration of iron atoms increases in the solid solutions, the integral intensity of the absorption signals changes (Fig. 5). The product of the peak intensity and the squared width of the derivative of the absorption line (by the extremum points), $r \Delta B_{p p}{ }^{2}$, we have used as a measure of the integral intensity of the absorption signal. The works $[18,27]$ have shown that as the concentration of iron atoms in the solid solutions of both series increases, the integral intensities of the absorption signals with $g \sim 2.0$ and $g=4.27$ grow. The intensity of the line with $g \sim 2.0$ significantly exceeds that of the $g=4.27$ one. This fact reveals the preference of minimally distorted sites by iron atoms.

The solid solutions $\mathrm{Bi}_{2} \mathrm{BaNb}_{2-2 x} \mathrm{Fe}_{2 x} \mathrm{O}_{9-\delta}$ as well as iron oxides $\mathrm{FeO}, \mathrm{Fe}_{2} \mathrm{O}_{3}$ and $\mathrm{Fe}_{3} \mathrm{O}_{4}$ were studied by the NEXAFS spectroscopy in order to determine the degrees of oxidation of iron atoms. The analysis of the NEXAFS Fe2p-spectra of iron-containing solid solutions and iron oxides (Fig. 6) revealed that the studied Fe atoms were mainly in the +3 oxidation state.

The pattern of the distribution of iron atoms in the solid solutions and the character of the exchange interactions in the clusters as a function of the paramagnetic atom fraction were elucidated by the theoretical calculation of the susceptibility and comparison of the obtained values with the experimental data.

The calculation of the experimental dependencies of $\chi^{\text {para }}(\mathrm{Fe})$ on concentration of the bismuth niobate solid solutions was performed in the context of the model of diluted solid solutions. According to this model, the magnetic susceptibility is determined as a sum of contributions of single paramagnetic atoms and their exchange-bound aggregates with antiferro- and ferro- magnetic exchange types:

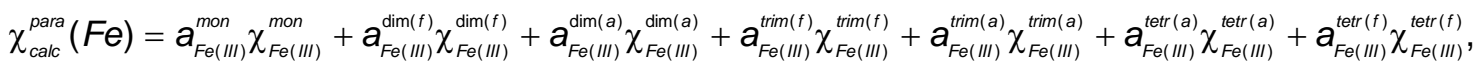

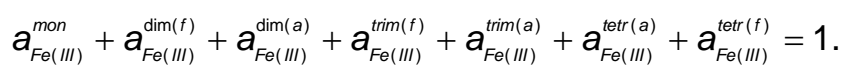

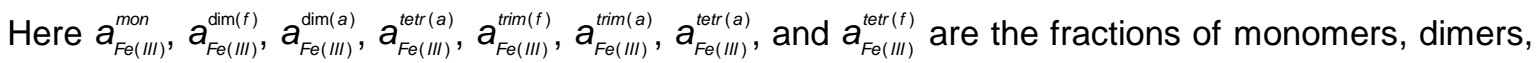
trimers, and tetramers of iron(III) atoms with ferro- and antiferromagnetic types of exchange, respectively;

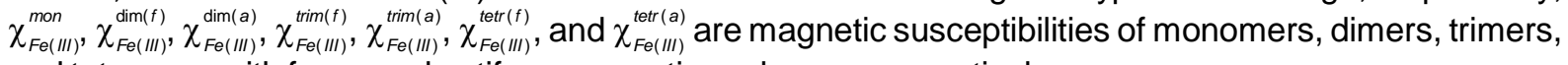
and tetramers with ferro- and antiferromagnetic exchange, respectively.

According to the Heisenberg-Dirac-van Vleck model [28], the magnetic susceptibility of tetramers formed of paramagnetic atoms and representing a flat square was calculated by Eq. (3):

$$
\chi_{\text {tetr }}^{S_{1}-S_{2}}=\frac{1}{4} \frac{\sum_{S^{\prime}} \sum_{S_{12}} \sum_{S_{34}} g^{2}\left(S^{\prime}\right) S^{\prime}\left(S^{\prime}+1\right)\left(2 S^{\prime}+1\right) e^{-E\left(J, S^{\prime}\right) / k T}}{8 T \sum_{S^{\prime}} \sum_{S_{12}} \sum_{S_{24}}\left(2 S^{\prime}+1\right) e^{-E\left(J, S^{\prime}\right) / k T}}
$$

with $E\left(J, S^{\prime}\right)=-J\left[S^{\prime}\left(S^{\prime}+1\right)-4 S_{1}\left(S_{1}+1\right)\right], S_{12}=S_{1}+S_{2}, S_{1}+S_{2}-1, \ldots,\left|S_{1}-S_{2}\right|$, $S_{34}=S_{3}+S_{4}, S_{3}+S_{4}-1, \ldots,\left|S_{3}-S_{4}\right|, S^{\prime}=S_{12}+S_{34}, S_{12}+S_{34}-1, \ldots,\left|S_{12}-S_{34}\right|$.

Here, $S_{1}, S_{2}, S_{3}$, and $S_{4}$ are spins of atoms in a tetramer; $S_{1}=S_{2}=S_{3}=S_{4}=5 / 2$ for the Fe(III)-O-Fe(III)-O$\mathrm{Fe}(\mathrm{III})-\mathrm{O}-\mathrm{Fe}$ (III) tetramer; $S^{\prime}, S_{12}$, and $S_{34}$ are the total spin of a cluster and intermediate spin moments; $g$ is Lande factor for iron(III) atoms, $J$ is the exchange parameter, and $T$ is the absolute temperature.

The best agreement between experimental and calculated data for the $\mathrm{Bi}_{5} \mathrm{Nb}_{3-3 x} \mathrm{Fe}_{3 x} \mathrm{O}_{15-\delta}\left(\mathrm{Bi}_{2} \mathrm{Ba}-\right.$ $\left.\mathrm{Nb}_{2-2 x} \mathrm{Fe}_{2 x} \mathrm{O}_{9-\delta}\right)$ solid solutions was obtained with the following antiferromagnetic exchange parameters in the dimers: $J_{\text {dim }}=-55 \mathrm{~cm}^{-1}\left(-65 \mathrm{~cm}^{-1}\right)$, in trimers: $J_{\text {trim }}=-40 \mathrm{~cm}^{-1}\left(-50 \mathrm{~cm}^{-1}\right)$, and in tetramers: $J_{\text {tetr }}=-20 \mathrm{~cm}^{-1}$ $\left(-30 \mathrm{~cm}^{-1}\right)$; in the case of ferromagnetic exchange: $J_{\text {dim }}==38 \mathrm{~cm}^{-1}\left(50 \mathrm{~cm}^{-1}\right)$ (Fig. 7). The comparison of experimental and theoretical values of magnetic susceptibilities of the solid solutions is given in Fig. 8 .

The study of magnetic characteristics of bismuth niobate solid solutions $\mathrm{Bi}_{2} \mathrm{BaNb}_{2-2 x} \mathrm{Fe}_{2 x} \mathrm{O}_{9-\delta}$ and $\mathrm{Bi}_{5} \mathrm{Nb}_{3-3 x} \mathrm{Fe}_{3 x} \mathrm{O}_{15-8}$ revealed some features. In both series of solid solutions at infinite dilution, iron atoms (III) are predominantly aggregated to give dimers, trimers, and tetramers with antiferro- and ferromagnetic types of exchange. The results of the calculation showed that the degree of aggregation of iron atoms and the indirect exchange parameters are higher in the clusters of the $\mathrm{Bi}_{2} \mathrm{BaNb}_{2-2 x} \mathrm{Fe}_{2 x} \mathrm{O}_{9-\delta}$ solid solutions than those in $\mathrm{Bi}_{5} \mathrm{Nb}_{3-3 x} \mathrm{Fe}_{3 x} \mathrm{O}_{15-\delta .}$. This fact can be explained by crystal structure of the solid solutions containing barium atoms. A special feature of barium-bismuth niobate is that barium atoms fill the space between perovskite blocks of niobium-oxygen octahedrons. These atoms depolarize orbitals of the oxygen atoms which form 


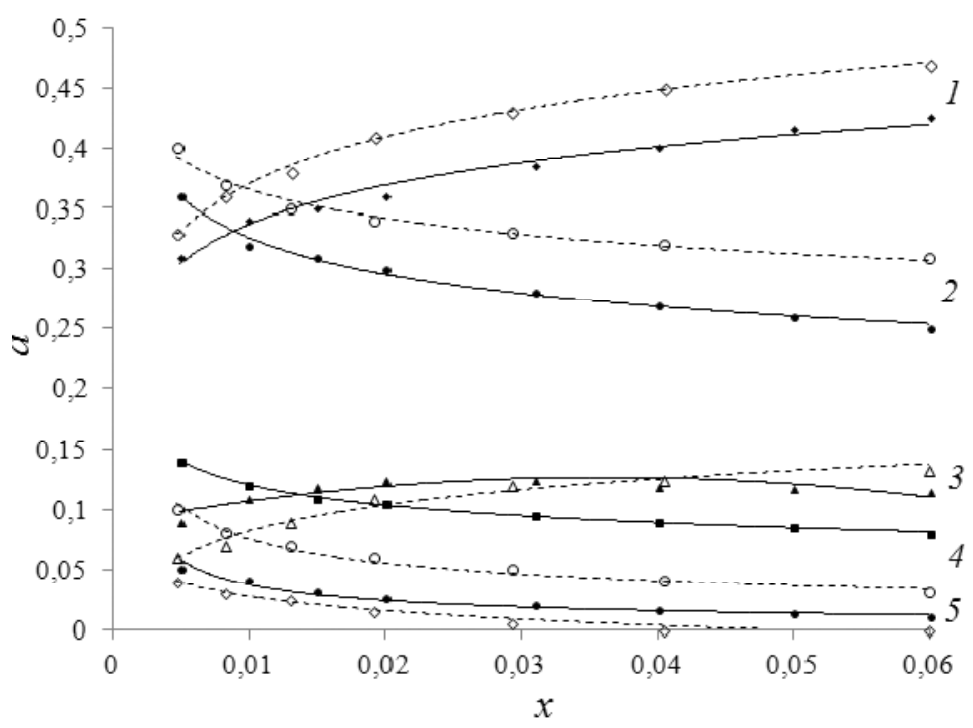

Fig. 7. Dependencies of the fractions of dimers with antiferromagnetic $a_{F e(I I I)}^{\operatorname{dim}(a)}(1)$ and ferromagnetic $a_{F e(I I I)}^{\operatorname{dim}(f)}(2)$ exchange types; fractions of trimers with antiferromagnetic $a_{F e(I I)}^{\text {tim(a) }}(3)$ and ferromagnetic $a_{F e(I I I)}^{\text {trim(t) }}(4)$ exchange types; fractions of tetramers with ferromagnetic (5) $a_{F e(I I)}^{\text {tetr }(f)}$ exchange type on the fraction of iron atoms in $\mathrm{Bi}_{2} \mathrm{BaNb}_{2-2 x} \mathrm{Fe}_{2 x} \mathrm{O}_{9-8}$ (solid lines) and $\mathrm{Bi}_{5} \mathrm{Nb}_{3-3 x} \mathrm{Fe}_{3 x} \mathrm{O}_{15-\delta}$ (dotted lines).
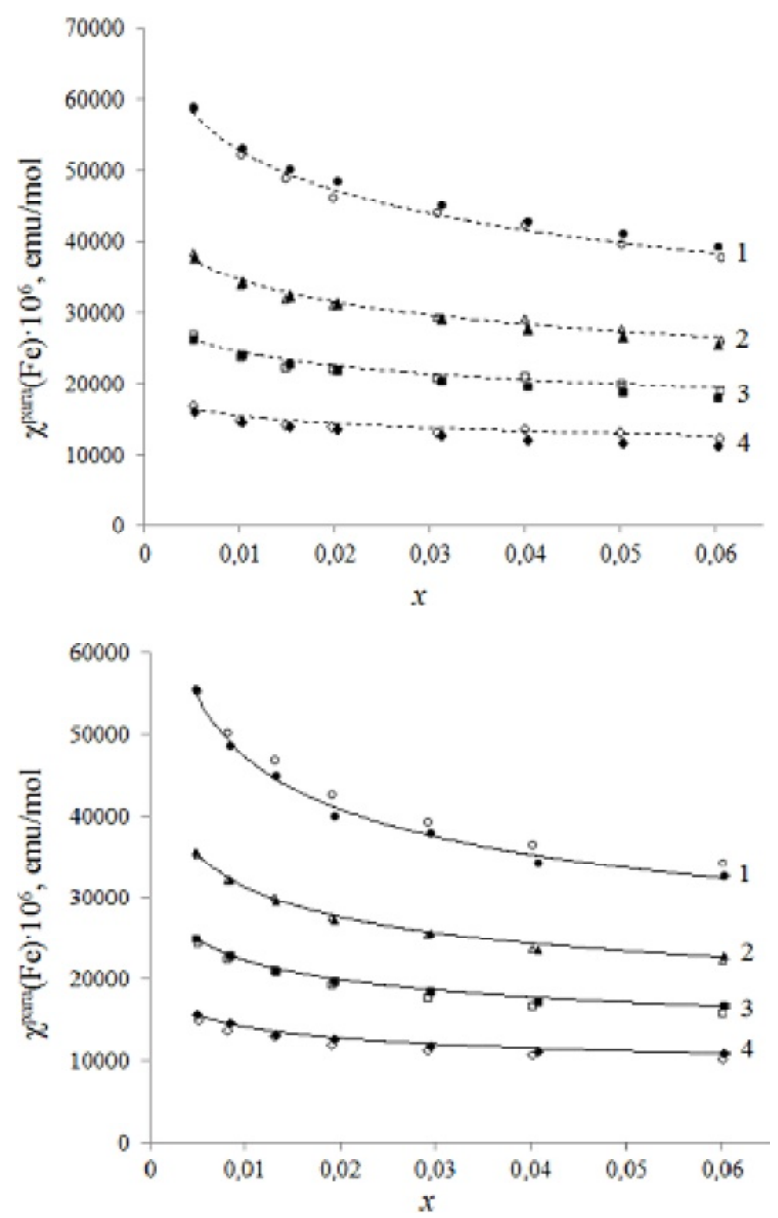

Fig. 8. Comparison of experimental and calculated values of the paramagnetic component of magnetic susceptibility of the iron-containing solid solutions $\mathrm{Bi}_{2} \mathrm{BaNb}_{2-2 x} \mathrm{Fe}_{2 x} \mathrm{O}_{9-\delta}$ (dotted lines) and $\mathrm{Bi}_{5} \mathrm{Nb}_{3-3 x}-$ $\mathrm{Fe}_{3 \mathrm{x}} \mathrm{O}_{15-\delta}$ (solid lines) at $90 \mathrm{~K}(1), 140 \mathrm{~K}(2), 200 \mathrm{~K}(3)$, and $260 \mathrm{~K}(4)$.

the coordination polyhedron of iron, thus the bond of the paramagnetic oxygen atom becomes more covalent. As a consequence, the overlapping of atomic orbitals of oxygen and the $d$-element increases and the magnetic exchange intensifies.

The formation of clusters with antiferro- and ferromagnetic types of exchange is an indirect evidence of iron (III) atoms being located in the crystal fields of various symmetry. The presence of antiferromagnetic type of exchange in the perovskite-like layered structure is not in doubt. The antiferromagnetic exchange between paramagnetic iron(III) atoms can be manifested within one perovskite-like layer of regular octahedra by the $d_{x^{2}-y^{2}}\left\|p_{x}\right\| d_{x^{2}-y^{2}}, d_{x^{2}-y^{2}}\left\|p_{y}\right\| d_{x^{2}-y^{2}}$ channels, and also between the planes by the $d_{z}\left\|p_{z}\right\| d_{z}$ channel. The ferromagnetic exchange between atoms of different valences is doubtful because of absence of other oxidation degrees of iron atoms.

An assumption on the possibility of ferromagnetic indirect exchange between $\mathrm{Fe}$ (III) atoms at the angle of $180^{\circ}$ in the crystal field of undistorted octahedral symmetry is in conflict with the theory of magnetic exchange [29]. However, geometrical distortions of the bond lengths and angles between paramagnetic atoms, and also anion vacancies inevitably resulting from heterovalent substitution contribute to the appearance of ferromagnetic exchange $[30,31]$. The monoclinic distortion of tetragonal structure of the bismuth niobate solid solutions associated with the incline of the $c$ axis to the plane of 
perovskite layers indirectly confirms such distortions. Moreover, the ESR spectra of the solid solutions confirm the fact that iron atoms are located in the fields of various symmetry.

\section{CONCLUSIONS}

Thus, it was shown that the magnetic behavior of iron-containing bismuth niobate solid solutions with perovskite-like layered structure is generally similar and is determined mainly by the crystal structure of the solid solutions, the symmetry, and the strength of the crystal field formed by ligands. The iron(III) atoms in solid solutions of heterovalent substitution aggregate forming strong clusters of iron atoms predominantly with the ferromagnetic type of exchange, which not disintegrate even at infinite dilution. The ESR and magnetic susceptibility methods have revealed that the iron atoms are located in the crystal fields of various distortion which results in the possibility of indirect magnetic exchange of anti- and ferromagnetic types. Iron atoms are selective in occupying cation sites in the unit cell of solid solution structure.

\section{REFERENCES}

[1] G.A. Geguzina, A.T. Shuvaev, E.T. Shuvaeva and V.G. Vlasenko // Cryst. Reports. 50 (2005) 52.

[2] V.A. Isupov // Ferroelectr. 189 (1996) 211.

[3] B.J. Macquart, B.J. Kennedy, T. Kamiyama and F. Izumi // J. Phys.-Condes. Matter. 16 (2004) 5443.

[4] N.A. Zhuk and I.V. Piir // Inorgan. Mater. 44 (2008) 1362.

[5] B. Aurivillius and P.H. Fang // Phys. Rev. 126 (1962) 893.

[6] L. Goux, J.G. Lisoni, M. Schwitters, V. Paraschiv, D. Maes, L. Haspeslagh and D.J. Wouters // J. Appl. Phys. 98 (2005) 054507.

[7] H. Yan, H. Zhang, R. Ubic, M.J. Reece, J. Liu, Z. Shen and Z. Zhang // Ceram. Adv. Mater. 17 (2005) 1261.

[8] B.J. Kennedy, Q. Zhou, Ismunandar, Y. Kubota and K. Kato// J. Sol. St. Chem. 181 (2008) 1377.

[9] R. Macquart, B.J. Kennedy and Y. Shimakawa // J. Sol. St. Chem. 160 (2001) 174.

[10] C.H. Hervoches and P. Lightfoot // J. Sol. St. Chem. 153 (2000) 66.

[11] Ismunandar, B.A. Hunter and B.J. Kennedy // Sol. St. Ion. 112 (1998) 281.

[12] B. Aurivillius // Ark. Kemi. 54 (1949) 463.
[13] I.J. Kennedy, B.J. Kennedy, M. Gunawan and Marsongkohadi // J. Sol. St. Chem. 126 (1996) 135.

[14] J. Gopalakrishnan, A. Ramanan, C.N.R. Rao, D.A. Jefferson and D.A. Smith // J. Sol. St. Chem. 55 (1984) 101.

[15] A. Lisinska-Czekaj, D. Czekaj, Z. Surowiak, J. Ilczuk and J. Plewa // J. of Eur. Ceram. Soc. 24 (2004) 947.

[16] T. Takenaka, K. Komura and K. Sakata // Jpn. J. Appl. Phys. 35 (1996) 5080.

[17] S. Tahara, A. Shimada, N. Kumada and Y. Sugahara // J. Sol. St. Chem. 180 (2007) 2517.

[18] N.V. Chezhina, D.A. Korolev, A.V. Fedorova, N.A. Zhuk, V.A. Butin, V.P. Lutoev, B.A. Makeev, S.S. Shevchuk and A.N. Nizovtsev // Russ. J. Gen. Chem. 87 (2017) 168.

[19] N.V. Chezhina, D.A. Korolev and A.V. Fedorova // Russ. J. Gen. Chem. 87 (2017) 373.

[20] R.D. Shannon // Acta Crystallogr. A 32 (1976) 751.

[21] L.G. Akselrud, Yu.N. Grin, P.Yu. Zavalij, V.K. Pecharsky and V.S. Fundamensky, In: Thes. Rep. XII Eur. Crystallographic. Meet. 3 (1985) 155.

[22] J. Stöhr, NEXAFS Spectroscopy (Springer, Berlin, 1992).

[23] T.J. Regan, H. Ohldag, C. Stamm, F. Nolting, J. Luning, J. Stöhr and R. L. White // Phys. Rev. B64 (2001) 214422.

[24] K. Yanovskij, V.I. Voronkova and I.N. Leonteva // Neorgan. Mater. 25 (1989) 834.

[25] G.I. Malovichkov, V.G. Grachev, O.F. Schirmer and B. Faust // J. Phys.: Condens. Matter. 23 (1993) 3971.

[26] A.G. Razdobarin, S.A. Basun, V.E. Bursian, L.S. Sochava and D.R. Evans // Sol. St. 52 (2010) 706.

[27] N.V. Chezhina, D.A. Korolev and N.A. Zhuk // J. Sol. St. Chem. 247 (2017) 8.

[28] Y.V. Rakitin, Introduction to Magnetochemistry. Method of Static Magnetic Susceptibility in Chemistry (Nauka, Moscow, 1980).

[29] J.B. Goodenough, Magnetism and the Chemical Bond (Metallurgy, Moscow, 1968).

[30] J.M. Coey, A.P. Douvalis, C.B. Fitzgelald and M. Venkatesan // Appl. Phys. Lett. 84 (2004) 1332.

[31] N.A. Zhuk, M.V. Yermolina, V.P. Lutoev, B.A. Makeev, E.A. Belyaeva and N.V. Chezhina // Ceram. Intern. 43 (2017) 16919. 